\title{
Relationship between Change of Diet and Poverty in Mexico: A Stochastic Analysis
}

\author{
Fatima Ezzahra Housni1 ${ }^{*}$, Humberto Bracamontes del Toro², Alejandro Macías ${ }^{1}$, \\ Virginia Gabriela Aguilera Cervantes ${ }^{1}$, Abdessamad Najine ${ }^{3}$, Isaí Guízar Mateos ${ }^{4}$ \\ ${ }^{1}$ Southern Region University Center, University of Guadalajara, Guadalajara, México \\ ${ }^{2} \mathrm{Cd}$. Guzmán Institute of Technology, Cd. Guzmán, México \\ ${ }^{3}$ Sultan Moulay Slimane University, Beni-Mellal, Morocco \\ ${ }^{4}$ Monterrey Institute of Technology, Zapopan, México \\ Email: *fatima.housni@cusur.udg.mx
}

Received 8 January 2016; accepted 20 February 2016; published 23 February 2016

Copyright (C) 2016 by authors and Scientific Research Publishing Inc.

This work is licensed under the Creative Commons Attribution International License (CC BY). http://creativecommons.org/licenses/by/4.0/

(c) (i) Open Access

\section{Abstract}

Background: In this article, we seek to break the paradigm of traditional estimates (deterministically) to estimate the probability of transition from poverty and diet change in Mexico through a stochastic model while providing a comparative study in the time between the diet change and poverty. Methods: A model based on the theory of Markov applied to the different dimensions of poverty and diet type from aggregate data from government agencies was used. Also likely future state changes were estimated and Monte Carlo simulation was used to find a balance between the transition probabilities of the different states. Results: It was shown that there was a high probability of consuming more fat than protein and carbohydrates in Mexico. In the case of poverty, it was found that poverty of patrimony presented the highest probability of change. Estimates for 2030 show as well that the Mexican population will have equal probabilities of state transition to the type of diet and poverty, as long as you consider changing some current values of both consumption and poverty. Conclusions: It was shown that there was indeed a close relationship between poverty of patrimony and an unbalanced diet where the probability of fat intake was high. The stochastic approach had enabled us, in addition to linking poverty and changing diet, to prevent the Mexican population of future scenarios that could be dramatic and, to avoid this situation, alternatives of change of state consumption and poverty had been proposed.

\section{Keywords}

Stochastic, Poverty in Mexico, Diet Change, Probability of Transition

\footnotetext{
${ }^{*}$ Corresponding author.
}

How to cite this paper: Housni, F.E., del Toro, H.B., Macías, A., Cervantes, V.G.A., Najine, A. and Mateos, I.G. (2016) Relationship between Change of Diet and Poverty in Mexico: A Stochastic Analysis. Food and Nutrition Sciences, 7, 83-89. 


\section{Introduction}

The relationship between low socioeconomic status and health is very complicated; it involves factors such as gender, age, culture, the environment, social and community networks, the lifestyle of people and behavior regarding health [1]. However, many population studies show that there are clear differences between social classes and the consumption of food and nutrients. That is, low purchasing groups have a higher level to carry an unbalanced diet and low fruit and vegetable consumption trend, and high income groups have more access to energy foods [2]. These habits can lead to both malnutrition (micronutrient deficiencies) as overfeeding (excessive energy consumption resulting in overweight and obesity) among members of a community, depending on the age, sex and level of poverty. Underprivileged people also develop chronic diseases at younger ages than those in higher socioeconomic groups often identified by their educational level and professional status.

From the above, we can clearly identify the close relationship between poverty and diet. On one side is the malnutrition that affects mainly children from marginalized strata, and secondly obesity and other chronic diseases affect children and adults in urban areas.

Poverty implies insufficiency of resources and mainly the basics like food and children are particularly suffering diseases associated with malnutrition and anemia, as well as diseases associated with sufficient food availability can only be achieved in urban areas [3]. However, most of the nutritional information has been used to define this relationship which is static indicators and deterministic models that come from studies at the national or regional nutrition surveys stocks [3] with the exception of some studies in regions or cities.

Then, this research seeks to break these classic paradigms that relate poverty and diet change, based on deterministic methods, now using a stochastic method that allows us to analyze the relationship between poverty and the type of diet, taking into account the probability of change as a purely stochastic behavior. The probabilistic correlation between poverty and the type of diet gives us a dynamic picture of its evolution and allows us to estimate preventive future scenarios. For this, the objective of this work is to estimate the relationship between diet change and poverty through a probabilistic stochastic model.

\section{Method}

In this work was used, on the one hand, a Markov model to estimate the probability of transition between the states of poverty and the transition probability of diet change from one state to another using aggregated data since 1990-2014, and on the other hand, the correlation between the two transition matrices was calculated which allowed us to understand the relationship between economic status and diet. In addition, a Monte Carlo simulation is used to project the results to the future, in order to predict trends of diet change and poverty.

The data of energy balance were taken from the United Nations for Food and Agriculture (FAO) [4] from 1990 until 2014. Then they were separated into three dimensions, based on their nutrient content carbohydrates per capita in Kcal/day, protein and fats. The concept is used synonymously with the balance of macronutrients, a measure of balance between calorie intake and energy expenditure in living organisms [5].

Regarding poverty in a multidimensional concept, CONEVAL [6] provides the following concepts of poverty: a) Food poverty: no ability to obtain a basic food basket (the set of essential goods and services and for workers and their families to meet their basic needs); b) Capability poverty: insufficient income to acquire the food basket value and make the necessary spending on health and education; c) Poverty of patrimony: insufficient income to acquire the food basket as well as perform the necessary expenditures on health, clothing, housing, transport and education; d) Income poverty: poverty measurement from the amount of income of households. For our study, we consider only three of the four concepts of poverty: food, capability and patrimony, from 1990 to 2014 as dimensions of the transition matrix. Since the desired relationship is about feeding and the estimate of income poverty the purchasing power of basic goods is not included, then the income poverty is not an important variable for our analysis.

For the problem, changing diet becomes a transition probability indicating the probability that a person in a vulnerable position $i$ at time $t$ pass to another dimension of vulnerability $j$ at time $t+1$. If $i=j$ then the transition probability becomes an indicator of the inability of the population (the sample) to overcome their vulnerability from one period to another. If $i \neq j$ then the transition probability can be interpreted as the relative mobility of the dimensional vulnerability $j$ in attracting dimension $i$. Therefore, a stochastic Markov process of first order, which consists in establishing the number of previous statements from which depends the probability of a state in a given moment of the process, is assumed. 
The probability distribution for mobility from one dimension to another of the population is conditioned upon its previous dimension. Therefore, each of the transition probabilities is conditioned on the size of the population in the previous period, so we can formulate the following transition probability matrix.

$$
\left[\begin{array}{ccccc}
P_{11} & P_{21} & P_{31} & \ldots & P_{n 1} \\
P_{12} & P_{22} & \ldots & \ldots & P_{n 2} \\
\vdots & \vdots & \vdots & \vdots & \vdots \\
P_{1 n} & P_{2 n} & \ldots & \ldots & P_{n n}
\end{array}\right]
$$

The transition probabilities are described as the portion of the population that is in any of the dimensions of vulnerability and dietary change to another dimension after a period of time.

The transition probabilities of a Markov process of first order can be estimated by using aggregate data that show the proportion of individuals in each of the different dimensions of both poverty and energy balance in each period. A multinomial logit model is used to estimate the probabilistic components of the state transition matrix [7]-[11].

For this procedure a system of equations with outputs $1,2,3, \ldots, m$ stored in $y$, and the explanatory variable $X$ is considered. In our case, we only consider our algorithm 3 outputs (the three Markov states or the three dimensions mentioned). Even though the outputs are coded as 1, 2 and 3, the numerical value is arbitrary since $1<2<$ 3 does not imply that output 1 is less important than the 2 or 3 . This property of $y$ where categories are not ordered makes a big difference in its use for estimating regressions (which is suitable for continuous dependent variables) for other algorithms as ologit (suitable for ordered categorical data), and the logit (suitable only for two outputs).

In the multinomial logit model (three states) a set of coefficients, $\beta^{(1)}, \beta^{(2)}$, and $\beta^{(3)}$ for each output it is estimated.

$$
\begin{aligned}
& \operatorname{Pr}(y=1)=\frac{\mathrm{e}^{X \beta(1)}}{\mathrm{e}^{X \beta(1)}+\mathrm{e}^{X \beta(2)}+\mathrm{e}^{X \beta(3)}} \\
& \operatorname{Pr}(y=2)=\frac{\mathrm{e}^{X \beta(2)}}{\mathrm{e}^{X \beta(1)}+\mathrm{e}^{X \beta(2)}+\mathrm{e}^{X \beta(3)}} \\
& \operatorname{Pr}(y=3)=\frac{\mathrm{e}^{X \beta(3)}}{\mathrm{e}^{X \beta(1)}+\mathrm{e}^{X \beta(2)}+\mathrm{e}^{X \beta(3)}}
\end{aligned}
$$

However, it is said that the model is unidentified in the sense that more than one solution for $\beta^{(1)}, \beta^{(2)}$, and $\beta^{(3)}$ carrying the same odds for $y=1, y=2$ and $y=3$. To identify the model, it is arbitrary so that $\beta^{(1)}, \beta^{(2)}$, or $\beta^{(3)}$ are zero, no matter what is chosen. That is, if we choose $\beta^{(1)}=0$, the remaining coefficients $\beta^{(2)}$ and $\beta^{(3)}$ will measure the relative change to $y=1$ group. If instead, we $\beta^{(2)}=0$, the remaining coefficients $\beta^{(1)}$ and $\beta^{(3)}$ will measure the relative change to $y=2$ group. The coefficients may differ because they have different interpretations, but the odds predicted for $y=1,2$ and 3 are the same. That is, any parameter will yield the same solution for the model.

Considering $\beta^{(1)}=0$ the equations become

$$
\begin{aligned}
& \operatorname{Pr}(y=1)=\frac{1}{1+\mathrm{e}^{X \beta(2)}+\mathrm{e}^{X \beta(3)}} \\
& \operatorname{Pr}(y=2)=\frac{\mathrm{e}^{X \beta(2)}}{1+\mathrm{e}^{X \beta(2)}+\mathrm{e}^{X \beta(3)}} \\
& \operatorname{Pr}(y=3)=\frac{\mathrm{e}^{X \beta(3)}}{1+\mathrm{e}^{X \beta(2)}+\mathrm{e}^{X \beta(3)}}
\end{aligned}
$$

The relative probability of $y=2$ to the base of output is 


$$
\frac{\operatorname{Pr}(y=2)}{\operatorname{Pr}(y=1)}=\mathrm{e}^{X \beta(2)}
$$

\section{Results}

\subsection{Application to Change of Diet}

A multinomial logit regression was used to adjust the transition model of change of diet considering that individuals are on a diet with predominance in protein, fat or carbohydrates. The transition matrix of (Table 1) shows the probability that an individual move from one state to another state of diet.

Transition probabilities of diet in the previous 24 years clearly shows that there is a high probability of consuming more fat than protein and carbohydrates in Mexico. The probability percentage of change of diet is alarming. The probability of people whose current diet is high in protein switch to fat is $99.16 \%, 98.74 \%$ of the people who currently consume more carbohydrates could go to consume more fats and $98.71 \%$ of people who consume a lot now fat diet remain unchanged. As you can see there is a great tendency that in the future the Mexican population consumes almost pure fat.

\subsection{Application to Poverty}

For this study were taken into account three dimensions of poverty: food poverty, capability poverty and patrimony poverty. Information concerning the amount of millions of people who have any of these dimensions of poverty for 24 years was collected. Samples were taken every two years since 1990 until 2014. The transition matrix of (Table 2) shows the probability that an individual move from one state to another state of poverty.

The highest probability of change is the poverty of patrimony. The probability of people who are in a state of food poverty switch to another state with patrimony poverty is $63.26 \%$. The probability of going from a state of poverty of capabilities to another with patrimony poverty is the $63.26 \%$ and the probability of remaining in the state patrimony poverty is $66.05 \%$. You can appreciate the high tendency to fall into a state of poverty of patrimony, since the probability is greater than $60 \%$.

\subsection{Future Trends with the Monte Carlo Method}

\subsubsection{Estimating the Probabilities by the Year 2020}

1000 Monte Carlo realizations considering only diet and poverty by 2020 are generated. The beginning of the random values as the latest values of the previous stage in 2014 is considered. The mean of the normal distribution is taken with the last value from the previous step. The standard deviation is considered the same as the preceding step. Table 3 shows the initial values.

The estimation of the transition probabilities by the year 2020 was based on the results of the probabilities of 2014. The purpose of conducting this kind of estimate the future is to understand the behavior of the diet and poverty following the same trends as before.

Table 1. Matrix of transition probabilities for the change of diet.

\begin{tabular}{cccc} 
& Protein & Fat & Carbohydrates \\
\hline Protein & $1.29 \%$ & $99.16 \%$ & $1.7316 \mathrm{e}-05 \%$ \\
Fat & $1.25 \%$ & $98.71 \%$ & $2.5887 \mathrm{e}-05 \%$ \\
Carbohydrates & $1.25 \%$ & $98.74 \%$ & $2.5788 \mathrm{e}-05 \%$ \\
\hline
\end{tabular}

Table 2. Matrix of transition probabilities for the change of poverty.

\begin{tabular}{cccc}
\hline & Food & Capability & Patrimony \\
Food & $28.93 \%$ & $5.6 \%$ & $63.26 \%$ \\
Capability & $31.14 \%$ & $5 \%$ & $63.26 \%$ \\
Patrimony & $31.14 \%$ & $5.6 \%$ & $66.05 \%$ \\
\hline
\end{tabular}


Table 3. Initial values for simulation Montecarlo.

\begin{tabular}{ccccccc}
\hline & Protein & Fat & Carbo & P_food & P_capab & P_patrim \\
\hline Mean & 351 & 842 & 1880 & $24.6 \mathrm{mill}$ & $33 \mathrm{mill}$ & $63.8 \mathrm{mill}$ \\
Std_Dev & 14.8 & 44.8 & 36.6 & $5.4 \mathrm{mill}$ & $6.0 \mathrm{mill}$ & $7.0 \mathrm{mill}$ \\
\hline
\end{tabular}

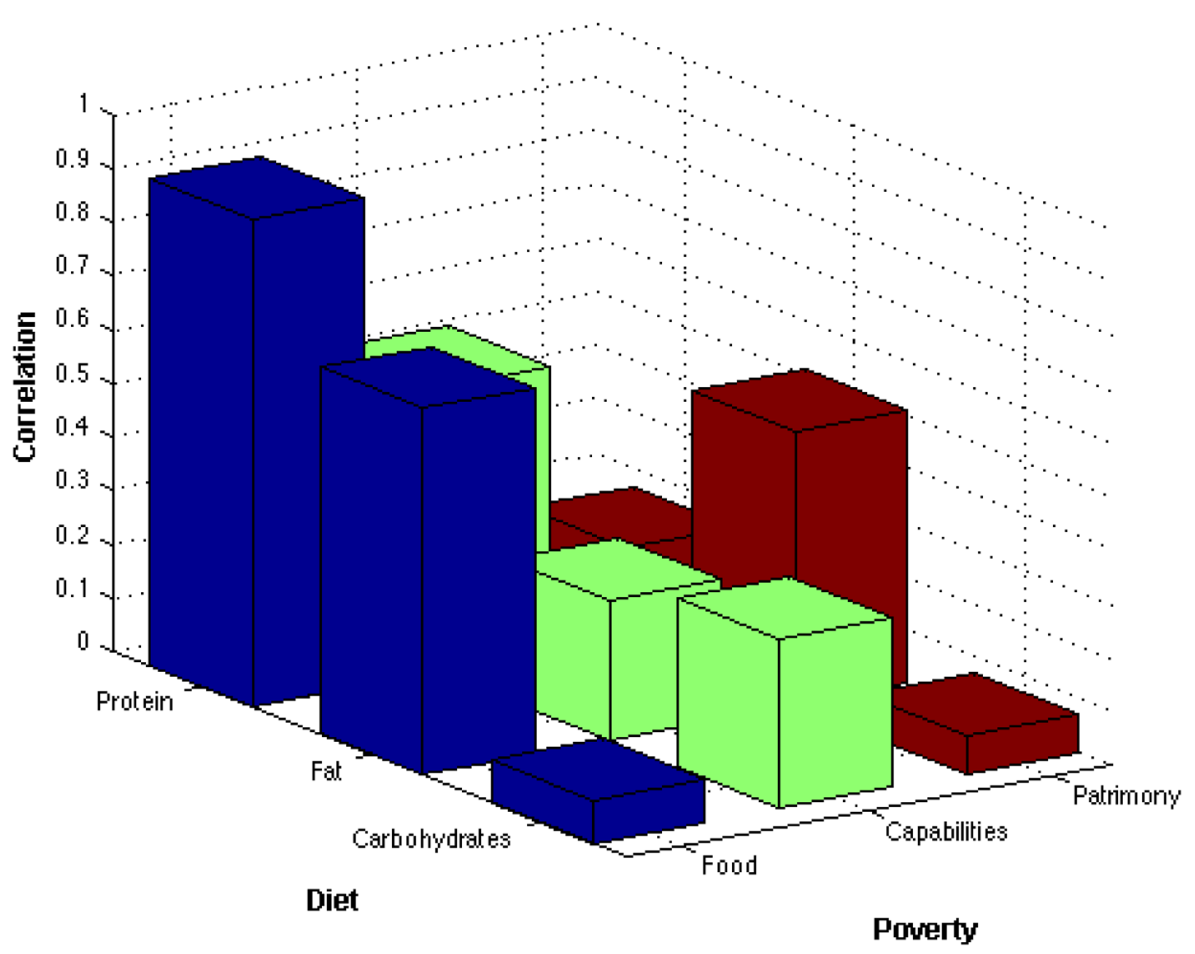

Figure 1. Cross correlation between poverty and dietary changes for 2020.

The results are shown in Figure 1. You can see that in 2020 it has a high probability that people consume as much protein and fat but fewer carbohydrates than in 2014. You can also appreciate the direct relationship between fat intake and patrimony poverty. That is, greater poverty of patrimony is greater the consumption of foods high in fat. Similarly it pronounced that capability poverty would be linked to a diet high in protein.

\subsubsection{Estimating the Probabilities by the Year 2030}

Now judiciously we modify the initial data of 2014 to find the values of variables more significantly. That is, we force the data to show results in which Mexico, by the year 2030, would have a balanced diet and the chances of passing from one state to another are almost equal. Then, from there, 1000 realizations for the estimation are considered. In each realization is assigned a different value to the average and standard deviation, these values are adjusted according to a positive normal distribution considering that it gives a certain growth in the population each year. We launched one thousand realizations in order to obtain the starting values for each dimension of poverty and diet.

The graph of the cross-correlation between poverty and the type of diet is shown in Figure 2.

Note that the results shown in Figure 2 are only a probability estimate. That is, you have the ability to simulate drastic or appropriate scenarios as required. The results allow us to take preventive measures before the problem becomes too big and that corrective actions are slow and difficult to address.

\section{Discussion}

The results obtained in this study show that there is indeed a close relationship between poverty of patrimony and an unbalanced diet where fat is what most consumed. This correlation obtained is the result of a collateral 


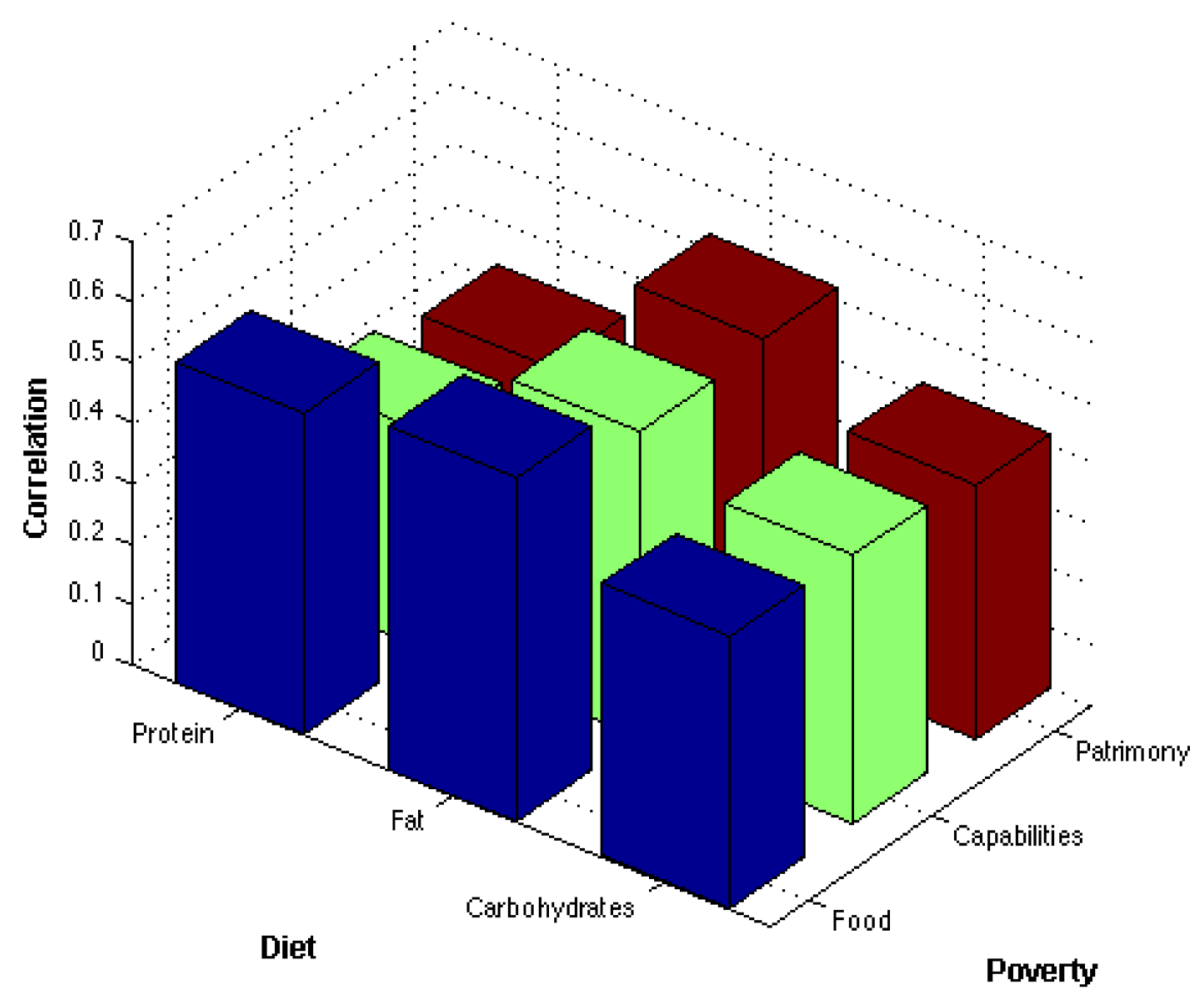

Figure 2. Cross-correlation between poverty and the type of diet to 2030.

anxiety when it is found, using a method of stochastic analysis that there is a high probability of consuming fatter than protein and carbohydrates in Mexico. The probability percentage of change of diet is alarming, the $99.16 \%$ of people who consume proteins can now switch to a diet rich in fat, $98.74 \%$ of people who currently consume carbohydrates tend to consume fats in the future and $98.71 \%$ people who consume fats can keep your diet for the future. That is, there is a great tendency that in the future the Mexican population consumes almost pure fat.

In the case of poverty, it is found that the highest probability of change is the poverty of patrimony. The probability of change from food poverty to poverty of patrimony is $63.26 \%$, the probability of change from capability poverty to poverty of patrimony is $63.26 \%$ and the probability of remaining in poverty of patrimony is $66.05 \%$. In other words, the trend shows that there is a probability of more than $60 \%$ of becoming poor of patrimony in the future.

Later, thousands of random values are treated to reach a balance between the states of the type of diet and dimensions of poverty in which the transition probabilities are almost equal. After thousands of launches is found that in 2030 the Mexican people can have the same state transition probabilities for the type of diet and poverty should be considered the following benchmarks: protein intake should be with an average of $351 \mathrm{kcal}$, fat of 550 kcal and carbohydrates of 1800 kcal. For poverty, the average person who will be in food poverty should be 31.6 million 33 million in capability poverty and 58 million in patrimony poverty.

So if we compare these data with those published by FAO and CONEVAL, today we can see that the diet should reduce fat intake rising from $842 \mathrm{kcal}$ in 2014 to $550 \mathrm{kcal}$ in 2030 meaning that must be reduced the consumption of $223 \mathrm{kcal}$ per person. For poverty should be reduced by the poverty of patrimony going from 63.8 million in 2014 to an average of 58 million by the year 2030 .

\section{References}

[1] Acheson, D. (1998) Independent Inquiry into Inequalities in Health. The Stationery Office, London.

[2] De Irala-Estevez, J., Groth, M., Johansson, L., Oltersdorf, U., Prattala, R. and Martinez-Gonzalez, M.A. (2000) A Systematic Review of Socioeconomic Differences in Food Habits in Europe: Consumption of Fruit and Vegetables. European Journal of Clinical Nutrition, 54, 706-714. http://www.nature.com/ejcn/journal/v54/n9/abs/1601080a.html 
http://dx.doi.org/10.1038/sj.ejcn.1601080

[3] Bourges, R.H. (2010) La alimentación y la nutrición en México. Comercio Exterior, 51(10). http://revistas.bancomext.gob.mx/rce/sp/articleReader.jsp?id=6\&idRevista=31

[4] Food and Agriculture Organization of the United Nations (2014) Food and Agriculture Organization of the United Nations Statistics Division. http://faostat3.fao.org/browse/FB/BC/E

[5] Pelto, G.H., Dufour, D. and Goodman, A. (2012). The Biocultural Perspective in Nutritional Anthropology. In: Goodman, A.D. and Pelto, G.H., Eds., Nutritional Anthropology: Biocultural Perspectives on Food and Nutrition, Oxford University Press, New York, 1-8.

[6] Consejo Nacional de Evaluación de la Politica de Dessarrollo Social (2014) Evolución de lasdimensiones de la pobreza 1990-2014.

http://www.coneval.gob.mx/Medicion/EDP/Paginas/Evolucion-de-las-dimensiones-de-la-pobreza-1990-2014-.aspx

[7] Greene, W.H. (2012) Econometric Analysis. 7th Edition, Prentice Hall, Upper Saddle River.

[8] Hosmer, D.W., Lemeshow, S.A. and Sturdivant, R.X. (2013) Applied Logistic Regression. 3rd Edition, Wiley, Hoboken. http://dx.doi.org/10.1002/9781118548387

[9] Long, J.S. (1997) Regression Models for Categorical and Limited Dependent Variables. Sage, Thousand Oaks.

[10] Long, J.S. and Freese. J. (2014) Regression Models for Categorical Dependent Variables Using Stata. 3rd Edition, Stata Press, College Station.

[11] Treiman, D.J. (2009) Quantitative Data Analysis: Doing Social Research to Test Ideas. Jossey-Bass, San Francisco. 